\title{
Gauging knowledge of developmental milestones among Albertan adults: a cross-sectional survey
}

Shivani Rikhy ${ }^{1,4,5}$, Suzanne Tough ${ }^{1,2,3^{*}}$, Barry Trute ${ }^{6}$, Karen Benzies ${ }^{7}$, Heather Kehler $^{4}$, David W Johnston ${ }^{4}$

\begin{abstract}
Background: Parental knowledge of child development has been associated with more effective parenting strategies and better child outcomes. However, little is known about what adults who interact with children under the age of 14 years know about child development.

Methods: Between September 2007 and March 2008, computer assisted telephone interviews were completed with 1443 randomly selected adults. Adults were eligible if they had interacted with a child less than 14 years of age in the past six months and lived in Alberta, Canada.

Results: Sixty three percent of respondents answered two (or more) out of four questions on physical development correctly. Fifteen percent of respondents answered two (or more) out of three questions on cognitive development correctly. Seven percent of respondents answered three (or more) out of five questions on social development correctly. Two percent of respondents answered three (or more) out of five questions on emotional development correctly. Parents and females were better able to identify physical developmental milestones compared to non-parents and males. $81 \%$ of adults correctly responded that a child's experience in the first year of life has an important impact on later school performance, $70 \%$ correctly responded that a child's ability to learn is not set from birth, $50 \%$ of adults correctly responded that children learn more from hearing someone speak than from television, and $45 \%$ recognized that parents' emotional closeness with a baby influences later achievement. Parents were most likely to use doctors/paediatricians, books, and nurses as resources. Among parents, there was no relationship between knowledge and parenting morale.

Conclusions: The majority of adults were unable to correctly answer questions related to when children under six years of age typically achieve developmental milestones. Knowledge of physical development exceeded knowledge about cognitive, emotional and social development. Adults were aware of the importance of positive experiences in influencing children's development. Strategies to improve awareness of developmental milestones combined with information on how to support optimal development may improve child development outcomes. Given that parents seek information about child development from health care providers there is an opportunity to ensure that providers are well informed about child development.
\end{abstract}

\section{Background}

Parents' knowledge of child development influences their expectations of, and interactions with, children [1-8]. Indeed, in developed countries, a mother's knowledge of child development has been positively correlated with her ability to enhance the development of her child [2,8-10]. Parents who were knowledgeable about child development demonstrated high parenting efficacy and competence. Conversely, those with poor knowledge

\footnotetext{
* Correspondence: suzanne.tough@albertahealthservices.ca

'Alberta Centre for Child, Family, and Community Research, Calgary, Canada
}

demonstrated poor parenting competence, regardless of their parenting efficacy $[5,6]$.

Evidence suggests that parents with poor knowledge of child development overestimate the rate of development, potentially leading to inappropriate expectations, impatience, and intolerance $[4,11]$. Indeed, parents with a history of abusing or neglecting their children demonstrated low levels of knowledge of child development and were frustrated by the children's inability to comply with their expectations [11-13].

Parents' knowledge of development as well as accurate and appropriate expectations for children's behaviour 
are key factors in parenting effectiveness, which is associated with better child outcomes $[2,10,14]$. Indeed, positive and effective parenting techniques are integral to healthy emotional and social development of children [15-18]. Conversely, ineffective parenting techniques, including inconsistent or harsh discipline, can increase the risk for conduct problems [19-21].

Lack of a warm positive relationship with an adult, or inadequate adult supervision, can increase the risk of social or behavioural problems in children [19]. The secondary consequences of behaviour, social, and conduct problems include school exclusion, delinquency, mental illness, partner violence and/or poor literacy [19,22-24]. The impact of these secondary outcomes, such as behaviour problems, has resulted in increased costs to governments in the education, social services, and justice. Children with behaviour problems have been estimated to cost the system ten times more then children without behaviour problems [25]. In summary, knowledge of child development appears to be a component of skilful parenting and optimal child development [2].

While parents, in particular mothers, show some knowledge of factors that support optimal child development [9], other evidence suggests that parental knowledge of children's development is limited in many areas [26]. Indeed, evidence from parents revealed gaps in knowledge about developmental milestones, developmental paths and the importance of the early social environment [26,27]. In addition parents reported limited knowledge of the beneficial forms of play, motivations for children's behaviours, discipline and spoiling [26]. However, despite some understanding of the gaps in parental knowledge of child development and parenting, little is known about what type of information or how much information parents require to support optimal child development. Even less is known about the level of knowledge, expectations, or quality of interaction of other non-parenting adults who also influence child development.

Mixed evidence regarding parental knowledge of child development, in addition to a lack of evidence about other adults' knowledge of child development, created an impetus for this study. This study assessed adults' understanding about child development; and among parents, where they access information about child development and their parenting morale.

\section{Methods}

\section{Population and Sampling Strategy}

Individuals were eligible to participate if they had interacted with children under the age of 14 years in the past 6 months, lived in Alberta, and were 18 years of age or older. Interaction was defined by the participant to recruit a sample of individuals that believed they were in contact with children sufficiently to participate. Participants were recruited through random digit dialling. Only one member of each household was eligible to complete an interview.

The sampling frame included telephone numbers of households from across the province of Alberta (population approximately 3 million). Respondents were stratified such that the first 1200 respondents were equally distributed between the urban centres of Calgary and Edmonton (each population about 1 million), and other rural regions (population approximately 1 million). The sample was also stratified to ensure that at least $25 \%$ of respondents were male. Stakeholders' interest in the survey allowed for oversampling from both Calgary and Edmonton.

\section{Study Design \& Questionnaire}

The survey was adapted with permission from one designed to assess parenting knowledge among parents living in the United States [26]. In addition, based on expert input, literature review, and community interest, questions were developed to address information gathering strategies, parenting morale, and opinions related to child care and children's issues. Questionnaire sections regarding knowledge of child development were aligned with local freely available material on child development [28] and were relevant to the Canadian context.

The questionnaire contained 17 questions relating to knowledge of developmental milestones in four developmental domains: physical development (four questions), cognitive development (three questions), social development (five questions) and emotional development (five questions). The Parent Morale Index contains 11 questions that ask about parenting experiences. A total of 34 questions concerned parents use of particular resources for information about child development and their relative satisfaction with each resource.

The study questionnaire was pre-tested with 10 randomly selected adult Albertans and based on their responses was modified for unclear wording and ease of use.

Structured telephone surveys were conducted. Survey questions addressed individuals' experience with children, knowledge of child development, and opinions about child care and children's issues. Parents of children under 14 years of age were asked additional questions about their parenting strategies, information gathering strategies, and parent morale.

\section{Survey Administration/Data Collection}

The survey was administered by trained interviewers using a Computer Assisted Telephone Interviewing system (CATI). Verbal agreement to begin the interview was accepted as consent for participation. 


\section{Outcome Measures}

The primary objective was to assess what adults who interacted with children under the age of 14 years understood about child development between birth and six years of age in four developmental domains: physical, cognitive, social and emotional development. Selected milestones were observable events such as walking, counting, and having best friends. Content areas and answers were taken from Growing Miracles, an evidence-based written resource provided to all new parents in the city of Calgary free of charge. Knowledge of child development was computed as a percentage score and dichotomised into two categories: 50 percent or more of questions correct versus less than 50 percent of questions correct for each developmental domain. Knowledge of child development was compared between sub-groups of interest including, males and females, urban and rural residents, as well as parents and nonparents.

For parent respondents, additional questions were asked about which specific resources were used to obtain child development information and their satisfaction with these resources. Parent morale, defined as parenting enthusiasm or positive spirits, was measured using the Parent Morale Index [29]. The Parent Morale Index (PMI) is a low-burden, 10-item scale developed to assess parents' energy and enthusiasm [29]. Parent morale, as measured by the PMI, has shown moderate associations with self-esteem and cognitive coping skills [29]. Low parent morale was defined as the 10 percentile and below of the sample distribution (score of 30 or lower). High parent morale was defined as the 90 percentile or higher of the sample distribution (score of 43 or above). The remaining scores (score of 31-42) were considered within the normal range.

\section{Sample Size}

It was calculated that at 80 percent power and significance level of $p \leq 0.05$, a difference in knowledge of 7.5 percent between parents and non-parents would be detected as statistically significant with a sample size of 685 parents and 758 non-parents. Additional calculations determined that at 80 percent power and significance level of $p \leq 0.05$, a difference in knowledge of 9.5 percent between males and females would be detected as statistically significant with a sample size of 300 males and 900 females.

\section{Data Analysis}

Data were downloaded from a password-protected CATI system, cleaned, and made available for analysis in SPSS/PC version 15.0 [30] and Stata SE Version 9.0 [31] programs. Significance was established at $\mathrm{p} \leq 0.05$. Analyses were based on all available data. The denominator varied slightly due to missing data for some questions.

Descriptive analysis and bivariate comparisons $\left(\chi^{2}\right.$ and t-test) were completed to assess differences in knowledge between males and females, parents and non-parents, as well as rural and urban residents. Similar comparisons were conducted to compare differences in parenting morale between parents with more or less understanding of child development. Between group comparisons for continuous variables used t-tests. Between group comparisons of categorical variables used chi-squared tests. When cell sizes were small, asymptotic significance values were reported.

Logistic regression models were developed to explore the relationship between understanding of physical development and demographic and other predictor variables. Models were expressed using odds ratios and 95\% confidence intervals. Independent variables were included in the regression analysis if they were found to be significant in a bivariate analysis (at $\mathrm{p}<0.05)\left(\chi^{2}\right.$ and t-test).

\section{Ethical Approval}

Ethical approval was granted by the Conjoint Health Research Ethics Board (CHREB) of the Faculties of Medicine, Nursing, and Kinesiology, University of Calgary, and the Affiliated Teaching Institutions. The study protocol was also reviewed and approved by the Arts, Science, and Law Research Ethics Board (ASL REB) at the University of Alberta.

\section{Results \\ Demographics}

The majority (85.9\%) of respondents were Caucasian and $55 \%$ of respondents had completed post secondary education (Table 1). Respondents had interacted with children in many capacities. Nearly half $(47.5 \%)$ of the respondents were parents of children under 14 years of age and $11 \%$ were parents of children with special needs (Table 2).

\section{Knowledge of Child Development}

Sixty three percent of parents answered two (or more) out of four questions on physical development correctly. Fifteen percent of parents answered two (or more) out of three questions on cognitive development correctly. Seven percent of parents answered three (or more) out of five questions on social development correctly. Two percent of parents answered three (or more) out of five questions on emotional development correctly (Table 3).

Adults' knowledge of child development was compared between parents and non-parents and between males and females (Table 4). Females were significantly more likely than males to answer $50 \%$ or more of the 
Table 1 Respondent Characteristics $(N=1443)$

\begin{tabular}{lr}
\hline & $\mathbf{n}(\%)$ \\
\hline Location & $399(27.7)$ \\
$\quad$ City of Calgary & $397(27.5)$ \\
$\quad$ City of Edmonton & $647(44.8)$ \\
$\quad$ Other Alberta & - \\
Gender & $370(25.6)$ \\
$\quad$ Male & $1073(74.4)$ \\
$\quad$ Female & - \\
Paid Job or Business & $1038(72.1)$ \\
$\quad$ Yes & $401(27.9)$ \\
$\quad$ No & - \\
Highest Education Level Attained & $340(23.7)$ \\
$\quad$ High School or Less & $302(21.1)$ \\
Technical School or Some College/University & $789(55.0)$ \\
College, University, or Post Graduate & $4(0.3)$ \\
Other & $45.73(14.50)$ \\
Age M(SD) & - \\
Ethnicity & $38(2.7)$ \\
Aboriginal & $21(1.5)$ \\
African/Caribbean/Black & $78(5.5)$ \\
Asian & $18(1.3)$ \\
Hispanic/Latino & $15(1.1)$ \\
Middle Eastern/Arabic & $1222(85.9)$ \\
Caucasian & $31(2.2)$ \\
Other & $210(17.2)$ \\
Household Income & $436(36.0)$ \\
$\quad$ Less than $\$ 39,999000$ to $\$ 79,999$ & $567(46.8)$ \\
\hline &
\end{tabular}

Table 2 Adults' interaction with children under 14 years of age $(N=1443)$

\begin{tabular}{lr}
\hline & $\mathbf{n ~ ( \% )}$ \\
\hline $\begin{array}{l}\text { Capacity of Interaction with child under 14 years } \\
\text { (not mutually exclusive) }\end{array}$ \\
$\quad \begin{array}{l}\text { Parent/Guardian/Primary Caregiver (child < 14 years } \\
\text { of age) }\end{array}$ \\
$\quad 695(47.5)$ \\
$\quad$ Of child/children with special needs \\
Grandparent & $80(11.7)$ \\
Other Relative (e.g., aunt, cousin) & $389(27.0)$ \\
Job/Paid Work & $463(32.1)$ \\
Volunteer Role & $306(21.2)$ \\
Other & $247(17.1)$ \\
\hline
\end{tabular}

questions on physical development correctly (66.0\% vs. $54.3 \%, \mathrm{p}=0.000)$. There were no significant differences between males and females regarding understanding of cognitive, social, and emotional developmental milestones. Parents were significantly more likely than nonparents to answer $50 \%$ or more of the questions on physical development correctly $(65.7 \%$ vs. $60.6 \%, \mathrm{p}=0.049)$.
There were no significant differences between parents and non-parents regarding understanding of cognitive, social, and emotional developmental milestones. There were no differences between rural and urban residents in the ability to identify the ages at which developmental milestones occur in any of the four developmental domains (data not shown).

When errors were made in regards to when a milestone is typically achieved, respondents were more likely to suggest the milestone was achieved sooner than typical, rather than later (data not shown). Indeed, in ten out of 17 milestones, more adults responded that the milestone occurred sooner than typical compared to later than typical.

Respondents were asked four questions related to practices that support child development (Table 5). Nearly $70 \%$ of respondents were aware that children's ability to learn is not set from birth and over $80 \%$ recognized that children's experiences in the first year of life have an important impact on school performance years later. Approximately $50 \%$ of adults recognize that children develop more language competency from listening to someone talk than from television. There were no significant differences between parents, non-parents, males or females regarding practices that support child development (Table 6). However, females (51.5\% vs. $44.1 \%, \mathrm{p}=0.013)$ and parents $(53.1 \%$ vs. $46.4 \%, \mathrm{p}=$ 0.011 ) were more likely to identify that children learn more language from conversation than from listening to television.

Logistic regression (Table 7) revealed that the most significant predictors for high scores on knowledge of physical development milestones included gender and parental status. Female gender (OR 1.66, 95\% CI 1.31-2.12) and being a parent (OR $1.29,95 \% \mathrm{CI}$ 1.04-1.60) increased the probability of obtaining high scores on knowledge of physical development milestones.

\section{Parents' Information Gathering Strategies}

Parents were asked whether they used certain publicly available resources to obtain information about child development. Over $90 \%$ of parents accessed doctors or paediatricians as a resource for information and nearly $65 \%$ of parents that sought information from physicians were very satisfied. Books were used as a resource for child development by $65.6 \%$ of parents and of these $50.9 \%$ were very satisfied. Nurses were a resource reported by $57.1 \%$ of parents and of these $62.6 \%$ were very satisfied. Although other resources, including religious leaders/groups, resource centres, and parenting classes were used by fewer parents, high levels of satisfaction were reported (Table 8). 
Table 3 Proportion of correct responses to $\mathbf{5 0 \%}$ or more of questions in each developmental domain as well as all domains $(N=1443)$

\begin{tabular}{|c|c|c|c|}
\hline & Correct Answer & Correct Responses & $50 \%$ or More Correct \\
\hline Developmental Domain or Milestone & - & $\mathrm{n}(\%)$ & $\mathrm{n}(\%)$ \\
\hline Physical Development & - & - & (2+/4 correct) 909 (63.0) \\
\hline Reach for Objects & 4-6 months & $740(51.3)$ & - \\
\hline Crawl & 6-12 months & $801(55.5)$ & - \\
\hline Walk & 12-18 months & $673(46.6)$ & - \\
\hline Dress Themselves & 24-36 months & $517(35.8)$ & - \\
\hline Cognitive Development & - & - & (2+/3 correct) $217(15.0)$ \\
\hline Engage in Pretend Play & 12-18 months & $162(11.2)$ & - \\
\hline Follow Simple Instructions & 12-18 months & $375(26.0)$ & - \\
\hline Begin Counting & 24-36 months & $564(39.1)$ & - \\
\hline Social Development & - & - & (3+/5 correct) 101 (7.0) \\
\hline Parallel Play & 18-24 months & $164(11.4)$ & - \\
\hline Share Toys & $36-60$ months & $453(31.4)$ & - \\
\hline Play Alone for 1 hour & $36-60$ months & $382(26.5)$ & - \\
\hline Have Best Friends & 60-72 months & $293(20.3)$ & - \\
\hline Show Empathy & 60-72 months & $73(5.1)$ & - \\
\hline Emotional Development & - & & (3+/5 correct) 24 (1.7) \\
\hline Differential Cries & 4-6 months & $321(22.2)$ & - \\
\hline Bond with Caregiver & 4-6 months & $145(10.0)$ & - \\
\hline Recognize Others' Emotions & 6-12 months & $198(13.7)$ & - \\
\hline Exert Independence & 12-18 months & $194(13.4)$ & - \\
\hline Advocate for Fairness & 60-72 months & $79(5.5)$ & - \\
\hline All Knowledge Domains & - & - & (9+/17 correct) 23 (1.6) \\
\hline
\end{tabular}

Table 4 Correct responses to $50 \%$ or more of knowledge questions by gender and parent status $(\mathrm{N}=1443)$

\begin{tabular}{|c|c|c|c|c|c|c|}
\hline & $\begin{array}{r}\text { Males } \\
\mathrm{n}=370 \\
\mathrm{n}(\%)\end{array}$ & $\begin{array}{r}\text { Females } \\
\mathrm{n}=1073 \\
\mathrm{n}(\%)\end{array}$ & p & $\begin{array}{r}\text { Parents } \\
\mathrm{n}=685 \\
\mathrm{n}(\%)\end{array}$ & $\begin{array}{r}\text { Non-parents } \\
n=758 \\
n(\%)\end{array}$ & $p$ \\
\hline Physical Development & $201(54.3)$ & $708(66.0)$ & 0.000 & $450(65.7)$ & $459(60.6)$ & 0.049 \\
\hline Cognitive Development & $49(13.2)$ & $168(15.7)$ & 0.263 & $108(15.8)$ & $109(14.4)$ & 0.462 \\
\hline Social Development & $25(6.8)$ & $76(7.1)$ & 0.906 & $47(6.9)$ & $54(7.1)$ & 0.918 \\
\hline Emotional Development & $5(1.4)$ & $19(1.8)$ & 0.814 & $13(1.9)$ & $11(1.5)$ & 0.542 \\
\hline
\end{tabular}

\section{Parent Morale Index}

Parents reported having moderate parenting morale $(\mathrm{M}=37.06, \mathrm{SD}=4.97)$, where moderate morale has been defined as a score of 31 to 42 . Parents' morale was not associated with knowledge of child development (Table 9).

\section{Discussion}

The respondents represented the urban-rural distribution of Alberta. Approximately half of respondents had obtained college, university, or post-graduate degrees and reported high annual incomes (annual household income of $\$ 80,000$ or more). Respondents represent adult Albertans who had interacted with children less than 14 years of age in the past six months and were interested in completing a survey on children. These results suggest that adults who interact with children under the age of fourteen are likely unfamiliar with the timing of a selection of physical, social, emotional, and cognitive developmental milestones that occur prior to age six years. Knowledge about social and emotional milestones was particularly poor. Despite an inability to identify when developmental milestones are typically

Table 5 Proportion of respondents that correctly identified effective parenting practices $(N=1443)$

\begin{tabular}{lr}
\hline & $\mathbf{n ( \% )}$ \\
\hline Children's ability to learn is not set from birth & $1009(69.9)$ \\
Children learn more from hearing someone in the same & $716(49.6)$ \\
room talk than hearing someone on television & \\
Parents' emotional closeness with their baby can strongly & $652(45.2)$ \\
influence how smart that baby becomes & 1257 (81.7) \\
A child's experiences in the first year of life have an & \\
important impact on school performance in later years &
\end{tabular}


Table 6 Proportion of respondents that correctly identified supportive strategies for child development by gender and parent status $(N=1443)$

\begin{tabular}{|c|c|c|c|c|c|c|}
\hline & $\begin{array}{r}\text { Males } \\
\mathrm{n}=370 \\
\mathrm{n}(\%)\end{array}$ & $\begin{array}{r}\text { Females } \\
\mathrm{n}=1073 \\
\mathrm{n}(\%)\end{array}$ & $p$ & $\begin{array}{r}\text { Parents } \\
\mathrm{n}=685 \\
\mathrm{n}(\%)\end{array}$ & $\begin{array}{r}\text { Non-parents } \\
n=758 \\
n(\%)\end{array}$ & $\bar{p}$ \\
\hline Children's ability to learn is not set from birth & $255(8.9)$ & $754(70.3)$ & 0.646 & $489(71.4)$ & $520(68.6)$ & 0.251 \\
\hline $\begin{array}{l}\text { Children learn more from hearing someone in the same room } \\
\text { talk than hearing someone on television }\end{array}$ & $163(44.1)$ & $553(51.5)$ & 0.013 & $364(53.1)$ & $352(46.4)$ & 0.011 \\
\hline $\begin{array}{l}\text { Parents' emotional closeness with their baby can strongly } \\
\text { influence how smart that baby becomes }\end{array}$ & $158(42.7)$ & $494(46.0)$ & 0.276 & $314(45.8)$ & $338(44.6)$ & 0.672 \\
\hline $\begin{array}{l}\text { A child's experiences in the first year of life have an } \\
\text { important impact on school performance in later years }\end{array}$ & $312(84.3)$ & $945(88.1)$ & 0.072 & $586(85.5)$ & $671(88.5)$ & 0.099 \\
\hline
\end{tabular}

Table 7 Adjusted odds ratios (OR) and 95\% confidence intervals $(95 \% \mathrm{Cl})$ of predictors for participants with low and high knowledge of physical developmental milestones

\begin{tabular}{|c|c|c|c|c|c|}
\hline \multirow[b]{2}{*}{ Demographic } & \multicolumn{2}{|c|}{ Physical Development } & \multirow[b]{2}{*}{ OR } & \multirow[b]{2}{*}{$95 \% \mathrm{Cl}$} & \multirow[b]{2}{*}{$\mathrm{p}$} \\
\hline & $\begin{array}{l}\text { Low } \\
\text { Knowledge } \\
\text { n/\% }\end{array}$ & $\begin{array}{l}\text { High } \\
\text { Knowledge } \\
\text { n/\% }\end{array}$ & & & \\
\hline \multicolumn{6}{|l|}{ Sex } \\
\hline Male & $169(45.7)$ & $201(54.3)$ & - & & 0.000 \\
\hline Female & $365(34.0)$ & $708(66.0)$ & 1.66 & $1.31-2.12$ & \\
\hline \multicolumn{6}{|l|}{ Parent Status } \\
\hline Non-Parent & $299(39.4)$ & $459(60.6)$ & - & & 0.023 \\
\hline Parent & 235 & $450(65.7)$ & 1.29 & $1.04-1.60$ & \\
\hline
\end{tabular}

Table 8 Proportion of parents that used resources for information about child development and their satisfaction with each resource $(N=685)$

\begin{tabular}{lrr}
\hline Resources & $\begin{array}{c}\text { Use } \\
\mathbf{n}(\%)\end{array}$ & $\begin{array}{c}\text { Very } \\
\text { Satisfied } \\
\mathbf{n}(\%)\end{array}$ \\
\hline $\begin{array}{l}\text { Doctor/Paediatrician } \\
\quad \text { Number of Developmental Specialists }\end{array}$ & $628(91.9)$ & $405(64.8)$ \\
$\quad$ Seen M(SD) & & \\
Books & $449(65.6)$ & $227(50.9)$ \\
Nurses & $390(57.1)$ & $243(62.6)$ \\
Phone Advice Services & $359(52.7)$ & $232(64.8)$ \\
Internet Websites & $359(52.5)$ & $112(31.5)$ \\
$\quad$ Number of Hours Monthly M(SD) & $6.75(20.10)$ & - \\
Community Health Centres & $345(50.7)$ & $194(56.4)$ \\
News Reports & $319(46.6)$ & $56(17.7)$ \\
Parenting Magazines & $277(40.5)$ & $78(28.4)$ \\
Childcare Providers & $221(32.3)$ & $123(55.9)$ \\
TV Shows & $189(27.6)$ & $49(25.9)$ \\
Religious Leaders/Groups & $176(25.7)$ & $118(67.0)$ \\
Resource Centres & $100(14.7)$ & $63(63.0)$ \\
Parenting Classes & $87(12.7)$ & $52(59.8)$ \\
Parenting Seminars & $65(9.5)$ & $33(50.8)$ \\
Social Workers & $66(9.6)$ & $27(41.5)$ \\
\hline
\end{tabular}

Table 9 Parenting morale index scores by level of knowledge among parents $(\mathrm{N}=685)$

\begin{tabular}{llll}
\hline & \multicolumn{2}{c}{ Knowledge } & \\
& $\begin{array}{l}\text { High } \\
\text { M (SD) }\end{array}$ & Low & M (SD) \\
\hline Parenting Morale Index & $37.59(4.79)$ & $36.89(5.01)$ & 0.118 \\
\hline
\end{tabular}

achieved, adults were able to identify some strategies that support optimal child development, including the value of in-person communication for language development.

Given the identified correlations between parental knowledge of development with parenting competence $[5,6]$, the possible role of parent morale was considered. However, this study identified that knowledge of child development was not linked to parents' morale or enthusiasm. While it is positive that parents felt positive about their role, additional consideration is needed to determine whether morale is linked with parenting competence. Indeed, morale may act as a motivator to seek services, and as such, if linked to competence, it may reflect a characteristic of those accessing parent support services.

Existing evidence suggested that knowledge of child development is related to appropriate expectations of and interactions with children [1-8,10,14]. Parents' knowledge of development as well as accurate and appropriate expectations for children's behaviour are key factors in parenting effectiveness, which is associated with better child outcomes $[2,10,14]$. Consequently, these data would suggest that a high proportion of parents may be unfamiliar with achievement of developmental milestones and may not be optimizing the use of strategies that support optimal development. Our findings suggest that despite limited knowledge about the timing of developmental milestones, parents do recognize some strategies that support children's development $[9,26,27]$. Of note, while parents' knowledge of child development is an important factor in supporting 
optimal child outcomes, it is less clear what knowledge is most closely linked with appropriate expectations of children.

Parents, and in particular, mothers, were best able to identify the timing of physical developmental milestones. Indeed, parents were 1.29 times as likely as non-parents to be able to identify the timing of physical developmental milestones. Further, females were 1.66 times as likely as males to be able to identify physical milestones. Although, not identified in this study, others have identified low educational attainment and parental age as additional risk factors for limited knowledge of child development $[1,32]$. While these studies focussed on particular populations of interest (rural communities or low-income women) and did not use random sampling, the findings may supplement those identified in this study. Educational attainment and parental age may not have been identified as risk factors in this study as the number of questions within each developmental domain was limited. Socio-cultural background has also been shown to influences parents' knowledge of child development and expectations of their children $[1,33]$. Indeed, previous work has suggested that Caucasian women (pregnant women or parents) were better able to identify effective discipline strategies and developmental capacities up to one year of age [1]. Another study identified that African parents were more likely to expect children to achieve milestones later than would be typical [33].

Parental knowledge of child development was found to moderate the relationship between socio-economic status (SES) and parent behaviour (child-directed speech) in an observational study [34]. While additional research findings suggest that educational strategies may be directed towards at-risk groups, including males, young parents, and individuals of Aboriginal decent and those with low or middle income, our study identified meaningful gaps in knowledge among well educated, high income adults, and those who interact with children. Given these findings, a population based approach, rather than a targeted approach, may be instrumental in improving global knowledge of child development.

While there has been substantial research to investigate the role of parents' knowledge in supporting children's development, there is limited evidence to indicate the role non-parenting adults play in the development of children. This study is the first to include the responses of non-parenting adults in a survey on knowledge of child development. Given that non-parents also had limited knowledge of developmental milestones, the study may illustrate a need to learn more about how to best provide evidence about child development and optimal strategies to shape child behaviour for those who are engaged with children, including teachers, child care providers, paediatric health care providers, volunteers, and recreation providers. These individuals' expectations of children and their patterns or interaction with children are relatively unknown, and yet many of these individuals spend a considerable amount of time with children during the formative years. There is an opportunity to ensure that all adults who interact with children and youth are well prepared to optimize development.

Doctors, books, and nurses were identified as the most commonly resources for information about child development for parents. Prior to widespread use of electronic resources, books and parenting magazines were a frequently cited resource for child development information [35]; however, increased availability of the internet is likely to alter how information is accessed [33]. Parents rely on information from their own families and it has been noted that mothers' knowledge of child development is significantly related to her mother's knowledge, even when contact between the two is minimal [33]. Given parents' level of knowledge about developmental milestones regardless of where they obtain information, there may be an opportunity to improve our understanding of the quality of the information obtained from routinely used resources. Given that doctors and nurses were the most commonly used resources, there is an opportunity to support these individuals in providing evidence-based and accurate information regarding children's development. Indeed, paediatric physicians and nurses, as well as family physicians, may be in most contact with children and families who are seeking information. Current strategies in Alberta include the dissemination of an evidence-based book on children's development to all new parents through physicians and nurses. It may also be necessary to consider novel approaches to disseminating information to parents and other adults about children's development.

The primary objective of this study was to better understand adults' knowledge of achievement of developmental milestones among children under six in four developmental domains; however, there were several limitations that may be addressed in subsequent research. The sample population was limited to individuals who were available by phone, English-speaking, and willing to participate in a 25-minute survey. These individuals may have an interest in this area and as such may not be representative of all adults who interact with children less than 14 years of age. Further, much of the sample was high income and Caucasian and as such the findings may not be generalizable to non-Caucasian ethnic groups or low income parents and adults. This sample is likely reflective of the middle class working public and of those who are volunteering with children in the public sector, indicating that there may be other populations at greater risk for limited knowledge of child 
development and poor developmental outcomes than currently identified.

The study is further limited in the number of questions per developmental domain. This limits the precision of our findings, and others interested in this area would be advised to increase the number of questions per domain for a more precise understanding of gaps in knowledge on early child development. We had limited variability in the responses to questions related to cognitive, social and emotional development, which handicapped the ability to undertake multivariate modeling. As noted, future studies with increased numbers of questions per domain may be warranted to further refine our understanding of knowledge gaps. Further, the scale has not been evaluated and therefore psychometric assessment of a scale to address knowledge may be warranted in additional work. The primary purpose of this study was to describe knowledge and consequently, this tool was not developed for clinical, diagnostic or prognostic assessment.

Despite these limitations, this study's findings substantiated and expanded upon previous research with the inclusion of non-parenting adults that may also be contribute to children's development. These findings further support existing evidence and suggest that the trajectory for better child outcomes may include parents' and adults' understanding of child development. Given the limited knowledge of developmental milestones, there is an opportunity to consider the current strategies to educate and inform parents, to work towards improving these strategies, and to expand strategies to include non-parenting adults.

\section{Conclusions}

1. There were meaningful gaps in knowledge of when children between the ages of birth and six achieve physical, emotional, cognitive and social milestones. Gaps in knowledge of child development existed among parents, non-parents, males and females. Females and parents were better able to identify physical milestones than were male counterparts.

2. Despite limited understanding of developmental milestones, there is early evidence that adults, both parents and non-parents, were aware of some strategies that can support children's optimal development.

3. Parents sought the support of physicians and nurses to obtain information on child development and were satisfied with the information they obtained, suggesting that these individuals are well-respected by parents and may be well positioned to disseminate accurate information to parents.

4. In this sample of parents, understanding of developmental milestones was not linked to parent morale.

\section{List of Abbreviations}

ASL REB: Arts, Science, and Law Research Ethics Board (University of Alberta); CATI: Computer Assisted Telephone Interviewing; CHREB: Conjoint Health Research Ethics Board (University of Calgary); NLSCY: National Longitudinal Survey of Children and Youth; SES: Socio-Economic Status.

\section{Author details}

${ }^{1}$ Alberta Centre for Child, Family, and Community Research, Calgary, Canada. ${ }^{2}$ Department of Paediatrics, University of Calgary, Calgary, Canada.

${ }^{3}$ Department of Community Health Sciences, University of Calgary, Calgary, Canada. ${ }^{4}$ Decision Support Research Team, Calgary Health Region, Calgary, Canada. ${ }^{5}$ Department of Child \& Youth Studies, Mount Royal University, Calgary, Canada. ${ }^{6}$ Faculty of Social Work, University of Calgary, Calgary, Canada. ${ }^{7}$ Faculty of Nursing, University of Calgary, Calgary, Canada.

\section{Authors' contributions}

SR coordinated the study, participated in data collection, performed the statistical analysis and was the primary author. ST provided the

conceptualization and design of the study, participated in statistical analysis, and participated in drafting the manuscript. BT participated in the conceptualization and design of the study and in the survey development. KB participated in the survey development and participated in the statistical analysis. HK participated in the conceptualization and design of the study. DJ participated in the survey development. All authors approved the final manuscript.

\section{Competing interests}

The authors declare that they have no competing interests.

Received: 11 May 2009 Accepted: 8 April 2010 Published: 8 April 2010

\section{References}

1. Reich S: What do mothers know? Maternal knowledge of child development. Infant Mental Health Journal 2005, 26:143-156.

2. Stevens $\mathrm{JH}$ : Child development knowledge and parenting skills. Family Relations 1984, 33:237-244.

3. Bell R: Parent, Child, and Reciprocal Influences. American Psychologist 1979, 34:821-826.

4. Cowen PS: Effectiveness of a Parent Education Intervention for At-Risk Families. Journal for Specialists in Pediatric Nursing 2001, 6:73-82.

5. Reiner Hess C, Teti DM, Hussey-Gardner B: Self-efficacy and parenting of high-risk infants: The moderating role of parent knowledge of infant development. Applied Developmental Psychology 2004, 25:423-437.

6. Conrad B, Gross D, Fogg L, Ruchala P: Maternal confidence, knowledge, and quality of mother-toddler interactions: A preliminary study. Infant Mental Health Journal 1992, 13:353-362.

7. Huang K-Y, Caughy MO, Genevro JL, Miller TL: Maternal knowledge of child development and quality of parenting among White, AfricanAmerican and Hispanic mothers. Applied Developmental Psychology 2005, 26:149-170.

8. Benasich AA, Brooks-Gunn J: Maternal attitudes and knowledge of childrearing: Associations with family and child outcomes. Child Development 1996, 67:1186-1205.

9. Parks PL, Stevens JH: Relationships among parenting knowledge, quality of stimulation in the home and infant development. Family Relations 1986, 35:411-416.

10. Dichtelmiller M, Meisels S, Plunkett J, Bozynski M, Claflin C, Mangelsdorf S: The relationship of parental knowledge to the development of extremely low birth weight infants. Journal of Epidemiology and Community Health 1992, 16:210-220.

11. Twentyman CT, Plotkin RC: Unrealistic expectations of parents who maltreat their children: An educational deficit that pertains to child development. Journal of Clinical Psychology 1982, 38:497-503.

12. Bavolek SJ: Assessing and treating high-risk parenting attitudes. Early Child Development and Care 1989, 42:99-112.

13. Azar ST, Rohrbeck CA: Child abuse and unrealistic expectations: Further validation of the Parent Opinion Questionnaire. Journal of Consulting and Clinical Psychology 1986, 54:867-868.

14. Hunt JM, Paraskevopoulos J: Children's psychological development as a function of the inaccuracy of their mothers' knowledge of their abilities. The Journal of Genetic Psychology 1980, 136:285-298. 
15. Assel MA, Landry SH, Swank PR, Steelman L, Miller-Loncar C, Smith KE: How do mother's childrearing histories, stress and parenting affect children's behavioural outcomes? Child: Care, Health \& Development 2002, 28:359-368.

16. Ateah CA: Disciplinary practices with children: Parental sources of information, attitudes, and educational needs. Issues in Comprehensive Pediatric Nursing 2003, 26:89-101.

17. Johnson JG, Cohen P, Chen H, Kasen S, Brook JS: Parenting behaviors associated with risk for offspring personality disorder during adulthood. Archives of General Psychiatry 2006, 63:579-587.

18. Riesch SK, Anderson LS, Krueger HA: Parent-child communication processes: Preventing children's health-risk behavior. Journal for Specialists in Pediatric Nursing 2006, 11:41-56.

19. Gardner F, Burton J, Klimes I: Randomized controlled trial of a parenting intervention in the voluntary sector for reducing child conduct problems: Outcomes and mechanisms of change. Journal of Child Psychology and Psychiatry 2006, 47:1123-1132.

20. Gardner F, Sonuga-Barke E, Sayal K: Parents anticipating misbehaviour: An observational study of strategies parents use to prevent conflict with behaviour problem children. Journal of Child Psychology and Psychiatry 1990, 40:1196.

21. Gardner F, Ward S, Burton J, Wilson C: The role of mother-child joint play in the early development of children's conduct problems: A longitudinal observational study. Social Development 2003, 12:361-379.

22. Fergusson D, Horwood L, Ridder E: Show me the child at seven: The consequences of conduct problems in childhood for psychosocial functioning in adulthood. Journal of Child Psychology and Psychiatry 2005, 46:837-849.

23. Robins L: Conduct Disorder. Journal of Child Psychology and Psychiatry 1991, 32:193-212.

24. Rydelius P: The development of antisocial behaviour and sudden violent death. Acta Psychiatrica Scandanavica 1988, 77:398-403.

25. Scott S, Knapp M, Henderson J, Maughan B: Financial cost of social exclusion: Follow up study of antisocial children into adulthood. British Medical Journal 2001, 323:191-194.

26. Yankelovich D, DYG Inc: What grown-ups understand about child development: A national benchmark survey. Washington, DC, Civitas Corporation, Zero to Three, Brio Corporation 2000, Ref Type: Report.

27. Invest in Kids: The parenting partnership - An Invest in Kids project. Invest in Kids 2007, Ref Type: Report.

28. Bullick T: Growing Miracles Quebecor Canada, Ltd 2005.

29. Trute B, Hiebert-Murphy D: Predicting family adjustment and parenting stress in childhood disability services using brief assessment tools. Journal of Intellectual \& Developmental Disability 2005, 30:217-225.

30. SPSS Inc: SPSS for Windows. [15.0]. Chicago 2003, Ref Type: Computer Program.

31. StataCorp: Stata Statistical Software. [9]. College Station, Texas 2010, Ref Type: Computer Program.

32. Pickett W, Marlenga B, Berg RL: Parental knowledge of child development and the assignment of tractor work to children. Pediatrics 2003, 112:11-16

33. Sistler AK, Gottfried NW: Shared child development knowledge between grandmother and mother. Family Relations 1990, 39:92-96.

34. Rowe ML: Child-directed speech: relation to socioeconomic status, knowledge of child development and child vocabulary skills. Journal of Child Language 2008, 35:185-205.

35. Geboy MJ: Who is listening to the "experts"? The use of child care materials by parents. Family Relations 1981, 30:205-210.

\section{Pre-publication history}

The pre-publication history for this paper can be accessed here: http://www. biomedcentral.com/1471-2458/10/183/prepub

\section{doi:10.1186/1471-2458-10-183}

Cite this article as: Rikhy et al:: Gauging knowledge of developmental milestones among Albertan adults: a cross-sectional survey. BMC Public Health 2010 10:183.

\section{Submit your next manuscript to BioMed Central and take full advantage of:}

- Convenient online submission

- Thorough peer review

- No space constraints or color figure charges

- Immediate publication on acceptance

- Inclusion in PubMed, CAS, Scopus and Google Scholar

- Research which is freely available for redistribution

Submit your manuscript at www.biomedcentral.com/submit
Biomed Central 